\title{
Development of innovative bio-inspired nanocomposites using electrophoretic deposition and hydrothermal recrystallization
}

\author{
C. A. Weiss, Jr. ${ }^{1}$, P. G. Malone ${ }^{1}$, R. D. Moser ${ }^{1}$, P. G. Allison ${ }^{1}$, \\ R. G. Hidalgo-Hernandez ${ }^{1}$, O. R. Negron ${ }^{3}$, M. Q. Chandler ${ }^{1}$, \\ S. W. Morefield ${ }^{2} \&$ K. Torres-Cancel ${ }^{1}$ \\ ${ }^{I}$ Geotechnical and Structures Laboratory, US Army Engineer Research \\ and Development Center, USA \\ ${ }^{2}$ Construction Engineering Research Laboratory, \\ US Army Engineer Research and Development Center, USA \\ ${ }^{3}$ Department of Mechanical Engineering, \\ University of Puerto Rico at Mayaguez, Puerto Rico
}

\begin{abstract}
For decades, researchers gradually unveiled the fascinating design principles that give biomaterials extraordinary properties and functionality. The US Army Engineer Research and Development Center (ERDC) is incorporating these design principles to develop hierarchical materials for structural applications. Electrophoretic deposition is one method being explored to create the hierarchical structures. This research details the synthesis of hierarchical nanocomposites composed of calcium carbonate by using electrotransport and electrophoretic deposition to migrate calcium and carbonate ions through a polymer matrix. This process allows better control of the crystal form, size, and location in the polymer matrix, allowing for fabrication of composite materials with optimized mechanical properties for various loading conditions. Other research efforts focused on the use of hydrothermal processing techniques to promote the oriented recrystallization of calcium carbonate. These techniques are being used successfully to fabricate composites for characterization and mechanical testing.
\end{abstract}

Keywords: nanocomposites, bio-inspired, electrophoresis, electro-transport. 


\section{Introduction}

Mineralized animal tissues, such as shells, bones, and scales, have unusually high strength and toughness properties that often exceed those of the minerals that form them. Their properties are attributable to their hierarchical spatial configurations. The micro- and nano-structural elements arrange hierarchically and typically have contrasting properties [1]. Nacre from molluses is a classic example of a successful bio-composite (fig. 1). The inorganic platelets that comprise the major structure of the nacre are formed from calcium carbonate in the form of aragonite with thicknesses of approximately several hundred $\mathrm{nm}$ and are typically 8 microns wide and 8 microns long. A thin layer (approximately $40 \mathrm{~nm}$ ) of a tough hair-like protein (conchiolin) separates each individual platelet in a single horizontal layer as well as individual layers of platelets from the ones above and below. Mineral bridges, $150-200 \mathrm{~nm}$ in diameter, connect each platelet to those above and below [2]. These mineral bridges are considered as extensions of the crystal that form in the pores in the scleroprotein and assure crystal continuity between tabular layers. Investigators have reported that in a fresh, moist shell the nacre composite has $\sim 3,000$ times the toughness (i.e., work of fracture) of a monolithic piece of aragonite [3-5]. The flexibility of the protein is critical to the toughness; in a dry shell, the composite is only as strong as the carbonate would be alone. This combination of a regularly ordered inorganic structure and a resilient organic matrix provides a mechanical strength similar to some ceramics but has increased ductility [6].

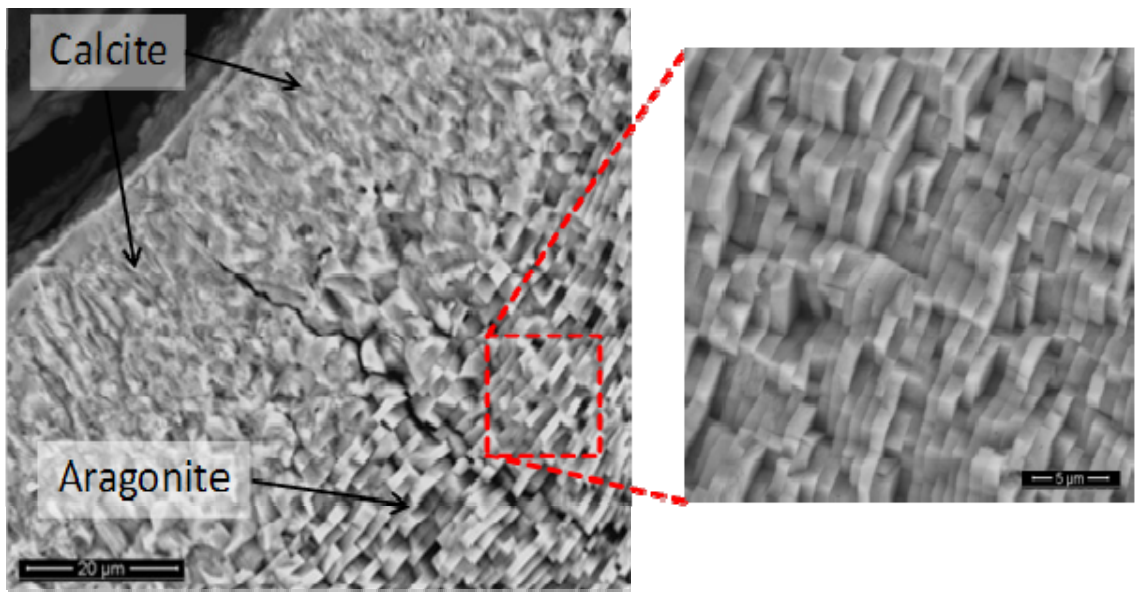

Figure 1: Cross section of a mussel shell showing the columnar calcite crystals in the outer shell layer and the tabular aragonite crystals in the nacre. 
Most investigators suggest that the major mechanism that controls the deformation of nacre is the interlamellar shearing as each layer of platelets moves past adjacent layers. In this process, the conchiolin layers around each platelet stretch. The irregularities and the micro- and nano-asperites on the surfaces of the platelets and the mineral bridges between layers provide the resistance to interfacial sliding. The complementary features in the surfaces between plates also produce a wedge-like locking effect [7]. However, this emphasis overlooks the importance of mineral micro-bridges. Based on the fine structure of nacre, Fan and Yilong [8] maintain that organic matrix layers of nacre should be considered as three-dimensional structures, and the microarchitecture of nacre ought to be described as a "brick-bridge-mortar" arrangement, not the traditional "brick and mortar" structure. Their research indicated that the mineral bridges not only can effectively enhance the stiffness, the strength, and the fracture toughness of the organic matrix layers of nacre, but also can play a significant role in the pattern of the crack extension in nacre.

A variety of layer-by-layer techniques, such as spraying, knife spreading, and brush application, was employed, especially with clays, for producing composites that have a nacre-like structure [9]. Clay-based nanocomposites were produced by centrifugal deposition (or spin coating) of montmorillionite clay from a polymer-based suspension. Some samples are reported to have a tensile strength of 70-80 MPa, a Young's modulus of 8-9 GPa, and a hardness of 1$2 \mathrm{GPa}[10]$.

Highly toughened artificial hybrid composites were made by freeze-casting alumina powder and then firing the resulting structure. The porous ceramic was then infiltrated with poly(methyl methacrylate). The ceramic and organic polymer composite had a toughness of over $30 \mathrm{MPa}^{1 / 2}$ and a tensile strength of 200 MPa [11]. Nacre-like clay composites were also prepared by depositing organically-treated gibbsite from an ethanol-water suspension using an electric field. The resulting clay-polymer films had tensile strengths up to $\sim 55 \mathrm{MPa}$ [12].

Carbonate composites that mimic nacre were investigated because of their potentially useful structural applications, their general bio-compatibility, and other properties such as fire and corrosion resistance. Fabrication was assisted by the ability of some carbonate precipitates (vaterite and aragonite particles) to cement together through recrystallizing to calcite [13]. A number of approaches were used to produce laminated carbonate composites. Layer-by-layer approaches involve the precipitation of $\mathrm{CaCO}_{3}$ on a thin polymer layer and the addition of successive layers to build up the composite [14]. Direct precipitation of acicular layers of vaterite or aragonite produce relatively small clusters of crystal platelets that resemble short sections of nacre, but the crystals are more acicular than tabular [15]. Wu et al. [16] developed a reinforced nacre-like structure by developing a laminar tabular array of carbonate crystals that incorporated silk fibroin. McKittrick et al. [17] explored novel fabrication techniques to develop similar composites. 
The present investigation examines the possibility of using a dual approach in which electro-transport and electrophoresis are used to infill the pore space in a thin, perforated polymer film to form bridges, followed by heat pressing layers of spheres of nano-crystalline vaterite between the films. The goal of this project is to develop the fabrication process and to determine if the process produces a useful composite with the laminar layers of carbonate and polymer and mineral bridges connecting the carbonate strata. The recrystallization under elevated temperatures and pressures should change both the mineralogy and morphology of the mineral phases.

\section{Materials and methods}

The fabrication system for nacre-like (organic polymer-mineral phase) composites that was investigated took advantage of the ability of nanocrystalline vaterite polymorph of calcium carbonate to recrystallize and develop aggregates of calcite crystals. Spheroidal aggregates of vaterite crystals were prepared by reacting solutions of ammonium carbonate and calcium acetate [18]. A polymer (polycarbonate) film that was used as the organic component and an electro-transport and electrophoresis technique $[19,20]$ was shown to fill pore spaces in the polymer and create the mineral bridges characteristic of nacre. Hydrothermal hot pressing was used to form the multi-crystalline aggregates between layers of the polymer [21].

\subsection{Precipitation of vaterite spheroids}

Vaterite was produced using a modification of the procedure by Prah et al. [18] based on direct addition of the reagents and continuous mixing. Equimolar $(0.5 \mathrm{M})$ solutions of ammonium carbonate (reagent-grade Certified ACS/NF, Fisher Scientific) and calcium acetate hydrate (ACS reagent grade). The calcium acetate solution was added to the stirred ammonium acetate solution at a constant rate of $25 \mathrm{ml} / \mathrm{min}$, and the reactants were held at $25^{\circ} \mathrm{C}$. The precipitate was collected by filtering (Whatman No. 42 filter paper), washed with distilled water, and dried to a constant weight at $105^{\circ} \mathrm{C}$.

The precipitates were fine enough to allow a backfilled powder mount to be prepared from the bulk samples. X-ray diffraction (XRD) analysis showed that the resulting precipitates were composed of a mixture of vaterite, calcite, and aragonite. Approximately $80 \%$ of the metastable phase was vaterite, with the rest being calcite and negligible amounts of aragonite (quantified by Rietveld analysis). Examination of samples of the precipitate (fig. 2) using an FEI Nova NanoSEM 630 field-emission variable-pressure SEM showed that the precipitate was composed almost exclusively of spherulites or clustered spherulites, a typical morphology of vaterite. A few rhombohedra (typical of calcite) were also observed (fig. 3). 


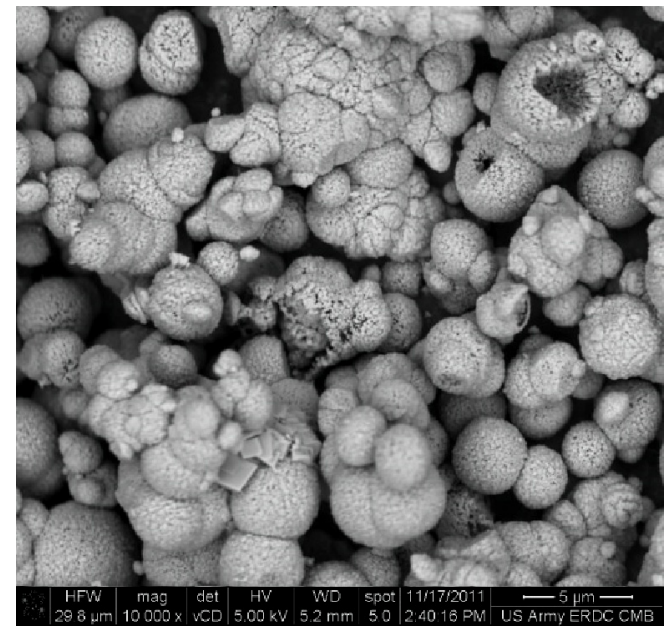

Figure 2: Example of precipitate produced by the ammonium carbonatecalcium acetate reaction.

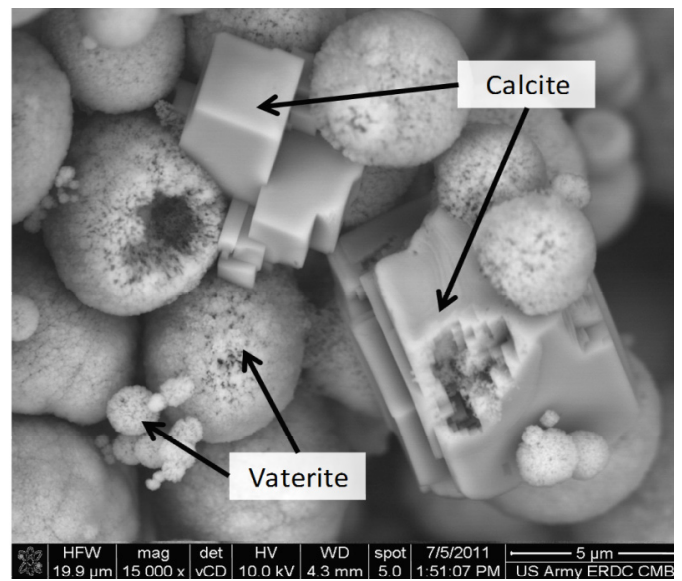

Figure 3: Example of recrystallization of unstable vaterite precipitate to calcite.

\subsection{Formation of mineral bridges by electrophoretic deposition}

The precipitation of vaterite in the pore spaces in the polycarbonate film was accomplished by electro-transport. A commercial filter holder was modified to hold a Whatman ${ }^{\circledR}$ nuclepore polycarbonate track-etch membrane (diameter $47.0 \mathrm{~mm}, \sim 22 \mu \mathrm{m}$ in thickness with a pore diameter $8.0 \mu \mathrm{m}$ ) between reagentfilled cells. Graphite electrodes were mounted in each cell so that a direct current could be passed through the membrane between the cells (fig. 4). 


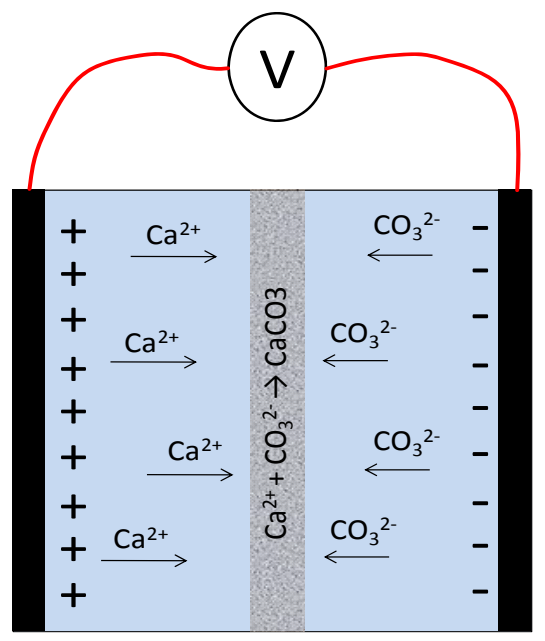

Figure 4: Schematic of electro-migration cell developed to produce precipitate within the membrane pore spaces.

The prepared membrane was densely covered with spheroidal masses of calcium carbonate (fig. 5). By varying the temperature and the voltage applied across the cell and the duration of the experimental run, a membrane could be prepared that was completely covered with a layer of a precipitate that was largely vaterite. The precipitate filled the pore holes and formed deposits that could, on recrystallization, become connections analogous to the mineral bridges in nacre.
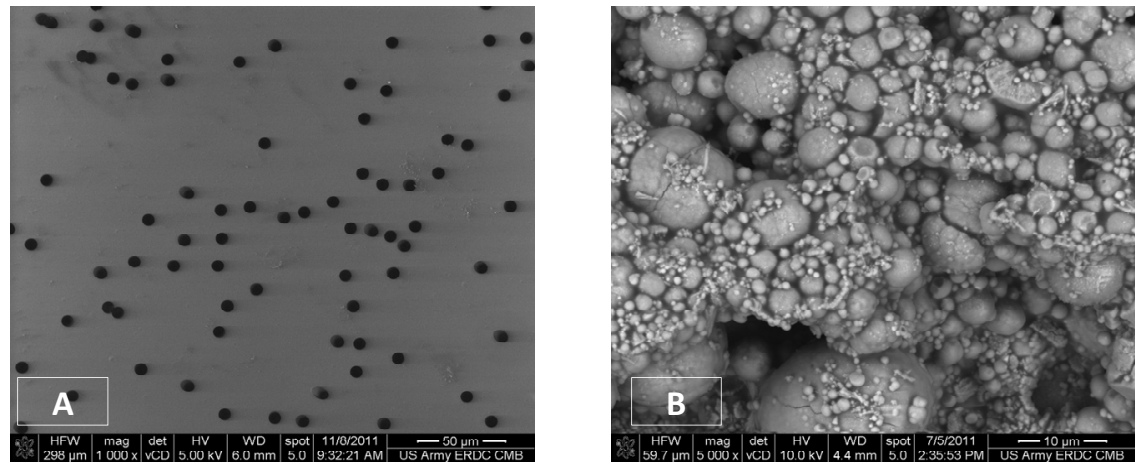

Figure 5: $\quad$ Surfaces of the polycarbonate membrane before (a) and after (b) deposition.

Increasing the voltage across the membrane increased the rate of transport and the proportion of vaterite being precipitated (fig. 6). 


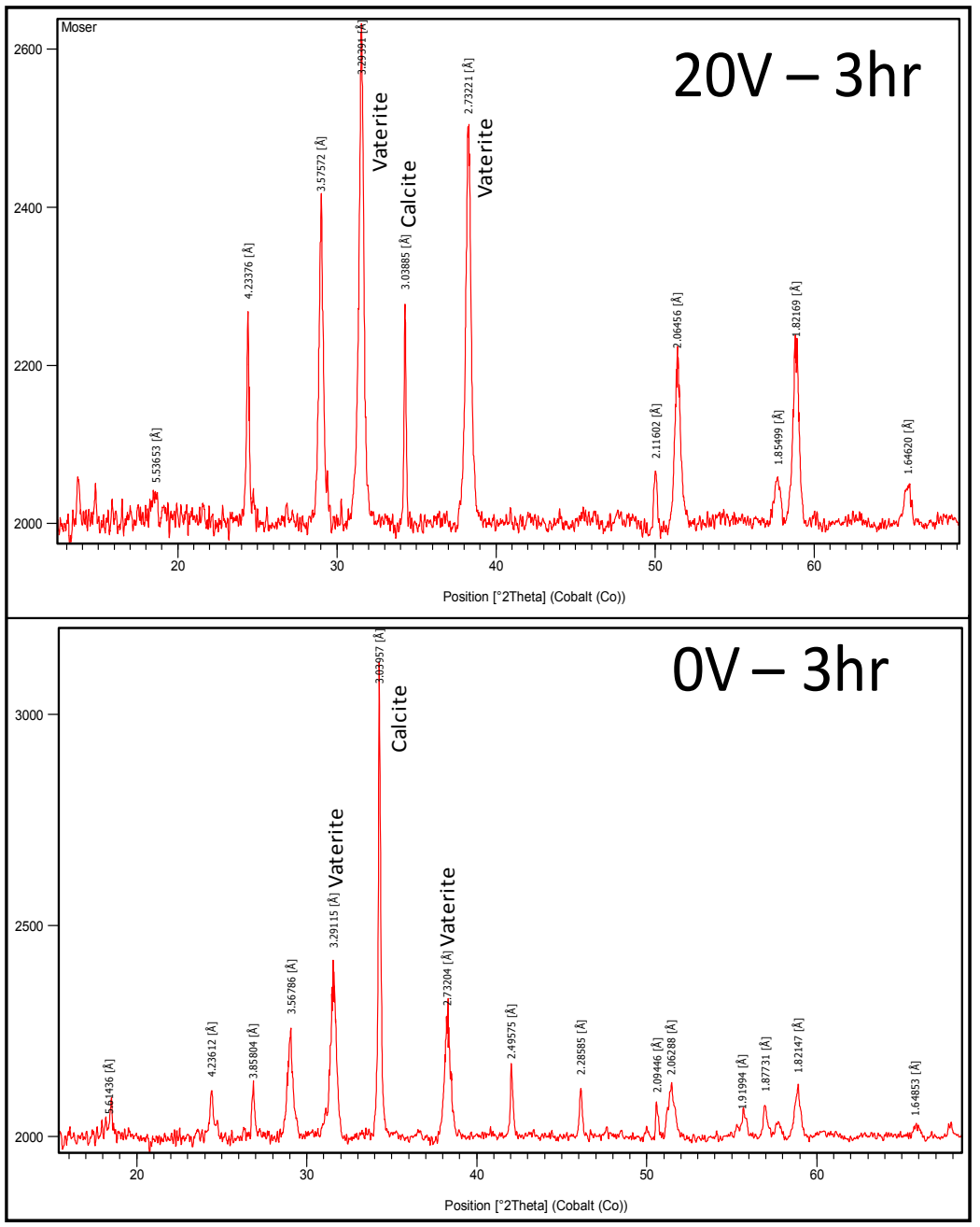

Figure 6: $\mathrm{X}$-ray patterns showing increasing vaterite with increasing voltage.

\subsection{Hydrothermal hot-pressing to assemble composites}

Hydrothermal hot-pressing (HHP), a method for causing the dissolution and reprecipitation of calcium carbonate, was used by Yamasaki et al. [21] to solidify precipitated calcite. The heat and pressure in the presence of a dilute alkali solution caused the initially rhombohedral crystals to become better compacted and cemented. Hot pressing of calcite resulted in reduced volume (shrinkage) and an approximately $75 \%$ increase in compressive strength. The current investigation began with calcium carbonate in the form of spherical masses of vaterite, and this polymorph was allowed to recrystallize to calcite under elevated temperature and pressure. The evaluation of the ability of hot pressing 
to promote the recrystallization of vaterite to form stable compacts of calcite was performed at a temperature of $100^{\circ} \mathrm{C}$ and uniaxial pressures up to $300 \mathrm{MPa}$ for periods up to $2 \mathrm{hr}$ using a PHI-Tulip Materials Testing Press Model 0235C (PHITulip Corp., City of Industry, CA). Deionized (DI) water was added to the precipitates prior to the HHP procedure at a water-to-carbonate ratio of 0.40 by mass. Layers of polycarbonate track-etched membranes were incorporated into the composite to act as an organic reinforcing matrix. The holes in the membranes allowed the formation of mineral bridges between the mineral layers. Sections and surfaces of the composites were prepared, and the samples were characterized using SEM and XRD techniques similar to those used to study the vaterite starting materials. Mechanical properties of nanocomposites were investigated using small plate-bending experiments in an Instron ElectroPuls E3000 high-resolution electromechanical testing frame.

\section{Results and discussion}

The approach to the fabrication of a composite with the structural features of nacre was undertaken by developing a procedure for reliably producing an unstable polymorph of calcite (vaterite) that could be recrystallized into stable calcite. Since recrystallization of vaterite proceeds with the dissolution of vaterite and the re-precipitation of the carbonate as calcite, the new crystals can bond together and re-grow with a different orientation. By taking advantage of the effect of pressure on making the direction perpendicular to the applied force, the preferred direction of growth, the new crystal mass can be formed in parallel or near-parallel crystallites as seen in nacre. The goal is to produce a composite that consists of layers of oriented crystallites reinforced with polymer sheets that serve the purpose of the conchiolin. The new composite mimics nacre in all its major features. Each step in production contributes to the overall task of making nacre-inspired composites.

\subsection{Deposition of vaterite in polycarbonate membranes using electro-transport}

Electro-transport was very effective at putting pore-filling carbonates into the holes in the polycarbonate film (fig. 7a). Both spheroidal vaterite and rhombohedral calcite were deposited on the surface of the polymer and in the pore space. Increasing the rate voltage across the membrane produced more rapid ion migration and increased the amount of spheroidal vaterite that was produced. As the carbonate deposits in the pores increased and the pores became more completely blocked, the current flow decreased. The deposition system controlled itself with the carbonate, depositing only where the current flow was not blocked (fig. 7b). 

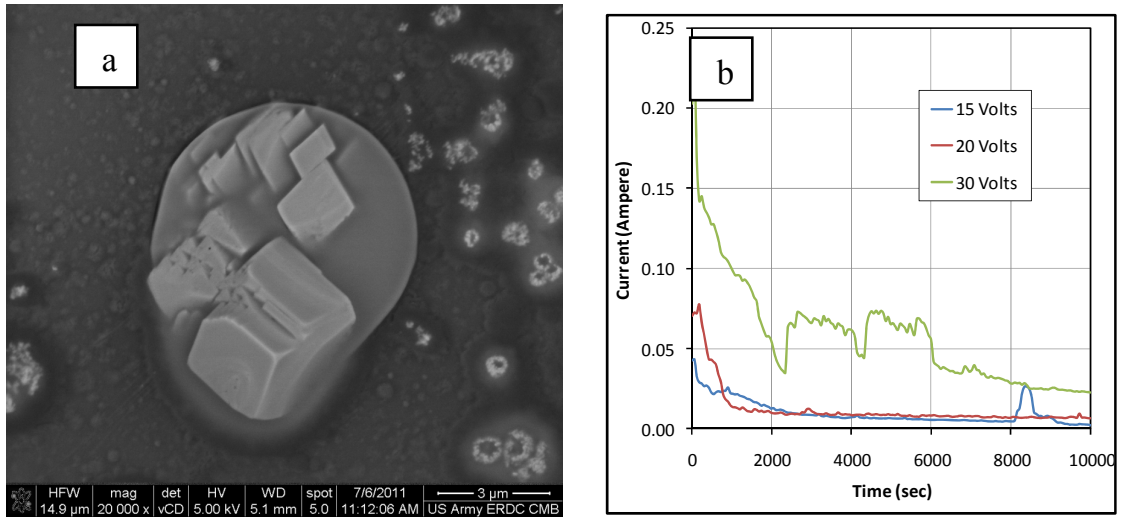

Figure 7: (a) Infilled pore showing calcite rhombohedra and amorphous carbonate gel and (b) drop-off of current in the electro-transport cell with increasing time during a carbonate precipitation run.

\subsection{Fabrication of composite by hydrothermal hot pressing (HHP) procedure}

The application of heat and pressure led to the near complete transformation of the starting material (primarily vaterite) to the stable calcite polymorph of calcium carbonate (fig. 8). It was found that at a temperature of $100 \mathrm{C}, 200$ and $300 \mathrm{MPa}$ confining pressures resulted in a complete transformation from vaterite to calcite. The spheroidal shape of the vaterite ended up producing radial arrays of long fibrous calcite crystals that were arranged with the long axis perpendicular to the direction of the applied pressure.
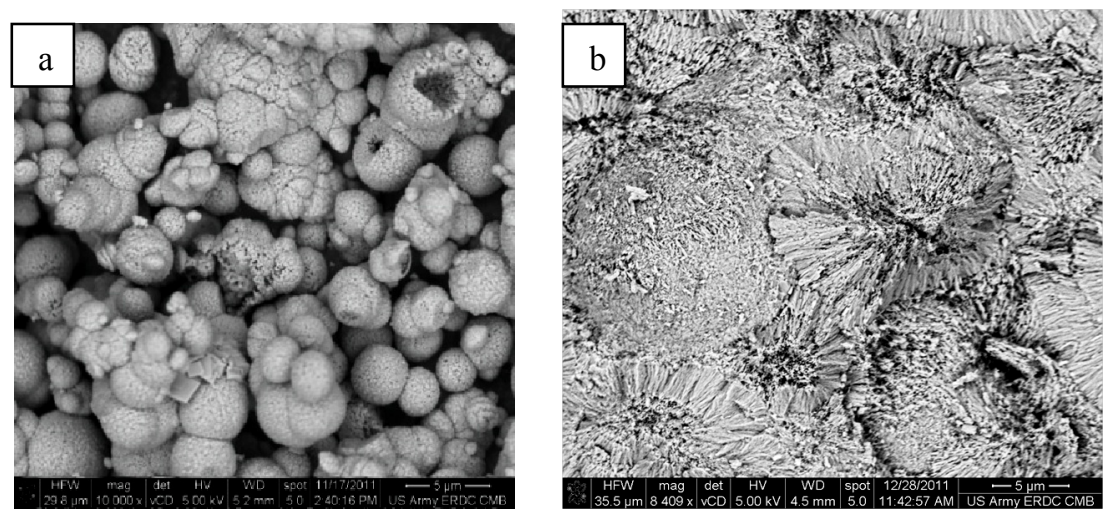

Figure 8: Vaterite spheroids before pressing HPP sample (a) prior to recrystallization and (b) after $\mathrm{HHP}$ at $100^{\circ} \mathrm{C}$ and $300 \mathrm{MPa}$. 
The completed composite (fig. 9), while not formed of tabular aragonite layers, shows features analogous to those observed in nacreous mollusk shells, which also exhibit wedge-like interlocking of mineral layers separated by an organic layer (polycarbonate). The perforations in the polycarbonate layer permitted the formation of mineral bridging between carbonate layers.

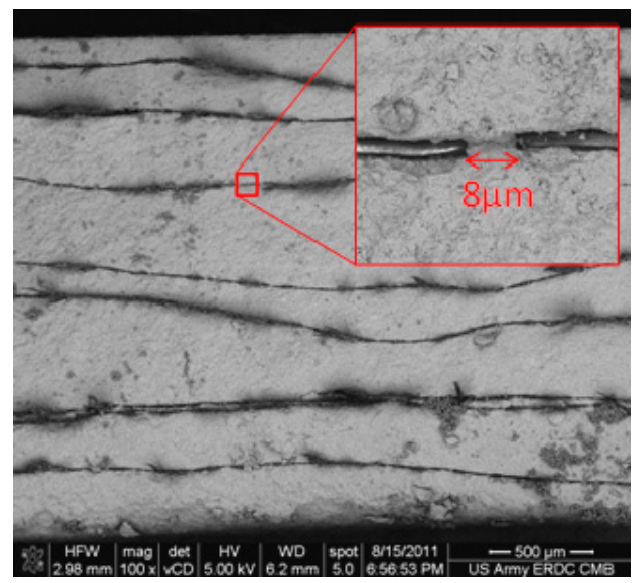

Figure 9: Composite produced by HHP procedure using $\mathrm{HHP}\left(100^{\circ} \mathrm{C}\right.$ and $100 \mathrm{MPa})$.

\section{Conclusions}

The approach to the fabrication of a composite with the structural features of nacre was undertaken by the following:

1. Developing a procedure for reliably producing an unstable polymorph of calcite (vaterite) that could be recrystallized into stable calcite. This was accomplished by using controlled direct mixing of concentrated $(0.5 \mathrm{M})$ ammonium carbonate and calcium acetate solutions.

2. Using electro-transport and electrophoresis to infill a track-etched polycarbonate membrane that could provide a conchiolin layer with mineral bridges. The production of vaterite on the membrane was accomplished by regulating the voltage across the membrane in a reaction cell.

3. Assembling layers of polycarbonate membranes and moistened vaterite to form a nacre-like structure.

4. Subjecting the layers to high pressures and temperatures using a heated press to cement the assembled composite. Since recrystallization of vaterite proceeds with the dissolution of vaterite and the re-precipitation of the carbonate as calcite, the new crystals can bond together and re-grow with a different orientation that is largely perpendicular to the direction of the applied pressure. 
5. Producing, through recrystallization of the carbonate, mineral bridges through pores in the track-etched membrane between layers, which allows the composite to act as a solid compact structure until shear stresses cause the mineral bridges to fracture and relative movement between the individual layers occurs. This action is very similar to that observed in nacreous layers in mollusc shells.

Electro-transport systems used with the HHP technique can potentially be a simple and viable option for manufacturing highly tailorable composites with mechanical properties that had a wide range of structural characteristics. Current research efforts focus on examining additional synthesis variables and examining the effects of impurities on the recrystallization of vaterite during HHP treatment. Further work will also examine systems for scaling up these synthesis techniques for the production of larger specimens for mechanical testing at quasi-static and high strain rates.

\section{Acknowledgements}

Support for this work was provided by the ERDC's Center-Directed Research Program. Permission to publish this document was granted by the Director, Geotechnical and Structures Laboratory.

This paper is not subject to copyright; it was written by one or more employees of the US Government in the course of their employment and as part of their duties with the US Army Corps of Engineers.

\section{References}

[1] Barthelat, F., Rim, J., \& Espinosa, H.D., A review on the structure and mechanical properties of mollusk shells - perspectives on synthetic biomimetic materials. In Applied Scanning Probe Methods XIII: Biomimetics and Industrial Applications, eds. B. Bhushan and H. Fuchs Springer, 2009.

[2] Checa, A.G., Cartwright, J.H., \& Willinger, M.G., Mineral bridges in nacre. J. Struct. Biol, 176(3), pp. 330-339, 2011.

[3] Jackson, A., Vincent, J., \& Turner, R., The mechanical design of nacre. Proc. of the Royal Soc. of London. Series B, Biol. Sci., 234(1277), pp. 415440, 1988.

[4] Currey, J.D., Currey, J.D., \& Estevez, J.A., Mechanical properties of mollusc shell. Symposia of the Society for Experimental Biology, 34(75), pp. 75-97, 1980.

[5] Wegst, U.G., \& Ashby, M.F., The mechanical efficiency of natural materials. Phil. Mag., 84 (21), pp. 67-81, 2004.

[6] Evans, A.G., Suo, Z., Wang, R.Z., Aksaya, I.A., He, M.Y., \& Hutchinson, J.W., Model for the robust mechanical behavior of nacre. J. of Mater. Res., 16, pp. 2475-2484, 2001. 
[7] Wang, R.Z., Suo, Z., Evans, A.G., Yao, N., \& Aksay, I.A., Deformation mechanisms in nacre. J. of Mater. Res., 16, pp. 2485-2493, 2001.

[8] Fan, S., \& Yilong, B., Mineral bridges of nacre and its effects. Acta Mechanica Sinica (English Series), 17(3), pp. 251-257, 2001.

[9] Wang, C-A., Le, H., \& Huang, Y., Rapid assembly processes of ordered inorganic/organic nanocomposites. Biomimetics: Learning From Nature, ed. Amitava Mukherjee, INTECH, Austria, 2010.

[10] Walther, A., Bjurhager, I., Malho, J.M., Pere, J., Ruokolainen, J., Berglund, L.A., \& Ikkala O., Large-area, lightweight and thick biomimetic composites with superior material properties via fast, economic, and green pathways. Nano Lett, 10(8), pp. 2742-2748, 2010.

[11] Launey, M., Munch, E., Alsem, D., Saiz, E., Tomsia, A., \& Ritchie, R.A., Novel biomimetic approach to the design of high-performance ceramicmetal composites. J. Roy. Soc. Interface, 6, pp. 741-753, 2009.

[12] Lin, T-H., Wei-Han, H., In-Kook, J., \& Peng, J., Bioinspired assembly of colloidal nanoplatelets by electric field. Chem. Mater., 21, (10), pp. 20392044, 2009.

[13] Zhou, G.-T., Yao, Q.-Z., Fu, S.-Q., \& Guan, Y.-B., Controlled crystallization of unstable vaterite with distinct morphologies and their polymorphic transition to stable calcite. Eur. J. Mineral., 22, pp. 259-269, 2010.

[14] Wei, H., Ma, N., Shi, F., Wang, Z.Q., \& Zhang, X., Artificial nacre by alternating preparation of layer-by-layer polymer films and $\mathrm{CaCO} 3$ strata. Chem. of Mater., 19, pp. 1974-1978, 2007.

[15] Dong, H.C., Yao, Y., Zhou, Y., Tong, G., Yan, D., Lai, Y., \& Li, W., Bioinspired synthesis of calcium carbonate hollow spheres with a nacretype laminated microstructure. Langmuir, 27 (1), pp. 366-370. 2011.

[16] Wu, Y., Cheng, C., Yao, J., Chen, X., \& Shao, Z., Crystallization of calcium carbonate on chitosan substrates in the presence of regenerated silk fibroin. Langmuir, 27 (6), pp. 2804-2810, 2011.

[17] McKittrick, J., Meyers, M.A., \& Jin, S., Synthesis of Nacre-Like Structures Using Novel Fabrication Techniques. Report Number 54614-MS-II.1, Feb. $18,2010$.

[18] Prah, J., Maček, J., \& Dražič, G., Precipitation of calcium carbonate from a calcium acetate ammonium carbamate batch system. J. of Crystal Growth, 324(1), pp. 229-234, 2011.

[19] Deman, J., Precipitation during electromigration of ions. Anal. Chem., 42(3), pp. 321-324, 1970.

[20] Morefield, S.W., Weiss, C.A., Malone, P.G., \& Hock, V.F., Infilling of pore spaces in mortar using electrically-driven solution transport systems. Porous Media and Is Applications in Science, Engineering, and Industry: 3rd International Conference, American Institute of Physics, Melville, NY, AIP Conf. Proc. 1254, pp. 266-270, 2010.

[21] Yamasaki, N., Tang, W., \& Ke, J., Low-temperature sintering of calcium carbonate by a hydrothermal hot-pressing technique. J. of Mater. Sci. Letters, 11(13), pp. 934-936, 1996. 